IRA-International Journal of Management \& Social Sciences

ISSN 2455-2267; Vol.14, Issue 01 (January, 2019)

Pg. no. 1-7.

Institute of Research Advances

http://research-advances.org/index.php/RAJMSS

Institute of

\title{
Assertiveness Training and Psycho-Education as Preventive Measures of Drug Abuse among Secondary School Students in Makurdi Local Government Area
}

\author{
Joyce M. Terwase ${ }^{1 \#}$, Nguher Abigail Akaagerger ${ }^{2}$ \& Moses Denen Chiahemba $^{3}$ \\ ${ }_{1,2,3}$ Department of Psychology, Benue State University, Makurdi, Nigeria. \\ \#corresponding author. \\ Type of Review: Peer Reviewed. \\ DOl: http://dx.doi.org/10.21013/jmss.v14.n1.p1 \\ How to cite this paper: \\ Terwase, J.M., Akaagerger, N.A., Chiahemba, M.D. (2019). Assertiveness Training and Psycho- \\ Education as Preventive Measures of Drug Abuse among Secondary School Students in \\ Makurdi Local Government Area. IRA-International Journal of Management \& Social Sciences \\ (ISSN 2455-2267), 14(1), 1-7. doi:http://dx.doi.org/10.21013/jmss.v14.n1.p1
}

(C) Institute of Research Advances.

(c) EY-NO

This work is licensed under a Creative Commons Attribution-Non Commercial 4.0 International License subject to a proper citation to the publication source of the work.

Disclaimer: The scholarly papers as reviewed and published by the Institute of Research Advances (IRA) are the views and opinions of their respective authors and are not the views or opinions of the IRA. The IRA disclaims of any harm or loss caused due to the published content to any party.

Institute of Research Advances is an institutional publisher member of Publishers International Linking Association Inc. (PILA-CrossRef), USA. The institute is an institutional signatory to the Budapest Open Access Initiative, Hungary advocating the open access of scientific and scholarly knowledge. The Institute is a registered content provider under Open Access Initiative Protocol for Metadata Harvesting (OAI-PMH).

The journal is indexed \& included in WorldCat Discovery Service (USA), CrossRef Metadata Search (USA), WorldCat (USA), OCLC (USA), Open J-Gate (India), EZB (Germany) Scilit (Switzerland), Airiti (China), Bielefeld Academic Search Engine (BASE) of Bielefeld University, Germany, PKP Index of Simon Fraser University, Canada. 


\begin{abstract}
This study investigated Assertiveness Training and Psycho-education as preventive measures of drug abuse among secondary school students in Makurdi Local Government Area. The study adopted a pre-test, post-test and control group experimental design with a $3 \times 2$ factorial matrix. The sampling techniques adopted were the simple random method where each student was given an opportunity to be selected, and randomization of experimental groups and the control group to the schools through balloting was also done. Drug abuse prevention questionnaire (DAPQ), a standardized instrument developed by Skinner (1982), with a reliability coefficient of .97 were used for data collection. A total of 40 secondary school students made up of 28 males and 12 females with ages ranging from 15-23 years took part in the study. They also had a mean age of 18.38 Three hypotheses were raised and tested. The results obtained revealed that firstly, assertiveness training and psycho-education have significant treatment effects in the prevention of drug abuse among secondary school students $(F(2)=6.88 ; P<0.05)$. Secondly, sex had no significant effect on prevention of drug abuse $F(1)=$ $0.32 ; P>0.05$ and thirdly, there was also no statistically significant interaction effects on drug abuse among secondary school students $F(2)=0.82 ; P>0.05$. Therefore, it is recommended that high premium is placed on developing and mainstreaming prevention programs on drug abuse into the school curriculum in secondary schools for students to become more assertive and acquire more knowledge on drugs and its effects on mental health.
\end{abstract}

Keywords: Assertiveness, Psycho-education, Drug abuse, Secondary school students.

\title{
Introduction
}

Drug abuse is considered a critical health-related social and economic problem in most countries (Jahromi, Mokri \& Ekhtyari, 2009). In the last three decades, the world has experienced shocking figures expressing drug abuse prevalence in societies, especially among teenagers and youths. The United Nation's Office of Crime and Drug Abuse Prevention has recently reported 185 million drug consumers worldwide and an increasing treatment demand all over the world. Iranian drug abuse prevention headquarters estimated 4.5 million opium consumers in Iran at the end of 2004 (Naderi, Bynazadeh, Safatian \& Peyvandi, 2009).

Drug abuse prevention in schools is a top priority in most countries and various well-designed studies have shown that preventive programs are likely to reduce illegal substance usage in youths and adolescents (David, Lorraine, \& Sacha, 2008). The reasons for this high priority for the prevention programs is that drug abuse by adolescents is a major public health concern in most countries and the political will to address this problem, until now, there have been no objective criteria available for deciding which program is effective and which one is not, this makes it very difficult for schools as well as for policymakers and institutions that grant funds for such programs to make a wellfounded choice among the available programs which include, Life-Skills Training, the programs of project Northland, project STAR, or the Healthy Schools and substance project (Gottfredson, \& Wilson, 2003).

Assertiveness training programmes are designed to improve an individual's assertive beliefs and behaviours, which can help the individual, change how they view themselves and establish self-confidence (Wesley \& Mattaini, 2008). Basically, assertiveness training is about raising an individual's self-confidence so as to increase their level of selfesteem and resilience. Iruloh and Amadi, (2008) added that assertive training helps to teach individuals how to assert themselves despite the intimidation and pressures coming from other people. The purpose of assertiveness training is to teach persons appropriate strategies for identifying and acting on their desires, needs, and opinions while remaining respectful of others especially for senior secondary school students who are prone to peer pressure. Assertiveness training is a broad approach that can be applied to many different personal, academic, health care, and work situations and has a decades-long history in mental health and personal growth groups, going back to the women's movement of the 1970s.

Psycho-education on the other hand is to educate clients about substance abuse, and related behaviours and consequences. Psycho-education is a professionally delivered treatment modality that integrates and synergizes psychotherapeutic and educational interventions. Many forms of psychosocial intervention are based on traditional medical models designed to treat pathology, illness, liability, and dysfunction. In contrast, psycho-education reflects a paradigm shift to a more holistic and competency-based approach, stressing health, collaboration, coping, and empowerment (Dixon, 1999). 
Drug abuse is a general problem in Nigeria today especially in areas where there is no adequate supervision such as monitoring of students and effective use of punishment for deviant behaviours. The curative, rehabilitative and legal modalities earlier employed to combat drug and substance abuse have not yielded appreciable results, many individuals and groups are now resorting to preventive measures which are better, cheaper and healthier. The best strategy for implementing and attaining this goal is through life skills training such as assertiveness training and the use of psycho-education but these methods are scarcely used.

This study sought to establish the general trend of the drug problem in secondary schools and critically analyze assertiveness and psycho-education as preventive measures. The findings will aid in evaluating whether these strategies have the potential to help the government in curbing the drug problem among the youths in secondary schools.

Basically, the objectives of the study include;

i. To examine the influence of assertiveness as a preventive measure of drug abuse among secondary school students.

ii. To examine the influence of psycho-education as a preventive measure of drug abuse among secondary school students.

iii. To examine the influence of assertiveness and psycho-education as a joint preventive measure of drug abuse among secondary school students.

\section{Hypotheses}

i. There will be a significant main effect of treatment in the prevention of drug abuse among participants.

ii. There will be a significant main effect of sex on the prevention of drug abuse among participants.

iii. There will be significant interaction effects of treatment and sex on the prevention of drug abuse among the participants.

\section{METHOD}

\section{Design}

This study is a pre-test, post-test and control group experimental design with a $3 \times 2$ factorial matrix. The two treatment groups and the control group will be made up of three rows: A1, A2 and A3, respectively (Table 1). Sex was used as a moderating variable which was categorized as male and female.

\section{Table 1: Factorial Design}

\begin{tabular}{|c|c|c|c|}
\hline Treatment Strategy & Male & Female & Group Total \\
\hline Assertiveness Training (AT) - A1 & A1 $\mathrm{B} 1=$ & A1 $\quad \mathrm{B} 2=$ & $\mathrm{n}=14$ \\
\hline Psycho-education Training (PT) - A2 & A2 $\mathrm{B} 1=$ & A2 $\mathrm{B} 2=$ & $\mathrm{n}=12$ \\
\hline Control Group - A3 & A3 $\mathrm{B} 1=$ & A3 $\mathrm{B} 2=$ & $\mathrm{n}=14$ \\
\hline Total & & & $\mathrm{N}=40$ \\
\hline
\end{tabular}

Key: A1 = Assertiveness Training, A2 = Psycho-Education, A3 = Control Group; Sex (Male and Female).

\section{Study Setting}

The study was carried out in Makurdi, Benue State. Benue State is the food basket of Nigeria with a population of 4,253,641 in 2006 census (Wikipedia, 2016). Makurdi local government is the capital of Benue with an area of 820 $\mathrm{km}^{2}$. The 2006 census put the population of the local government at 300,377. The setting of this study constitutes 
three selected secondary schools which are Government Model secondary school Makurdi, Trinity Model Academy Makurdi and Padopads Harmony secondary school Makurdi. These schools are co-educational schools.

\section{Participants}

The participants for this study were made up of Secondary School Students from three Secondary Schools within Makurdi metropolis and a total of 40 students comprising both male and female were adopted. In order to sample participants for this study, a simple random method was adopted to afford each student the opportunity of being selected. Forty (40) students were sampled from three schools and assigned to groups through balloting. The various schools were randomized to the treatment and control groups. Participants were not supposed to be exposed to themselves to avoid contamination and attrition.

\section{Instruments}

This study used a drug abuse prevention questionnaire (DAPQ), a standardized instrument developed by Skinner (1982). The questionnaire comprised three sections beginning with the Consent for participation page. Section A contained student's bio-data while section B contained items on drug abuse. The questionnaire was tested for reliability and validity after the pilot study and reliability of .97 were got revealing very high reliability.

\section{Procedure of Treatment}

The treatment periods spanned five weeks of five sessions during which the researcher and participants interacted. The research took place in five stages; recruitment, pre-test, treatment, post-test and evaluations.

The researcher began by giving consent forms to those selected for the study. These forms were to seek their cooperation during the period of treatment. To ensure that the participants were regular at the sessions, incentives were provided such as pens, jotters and snacks. A research assistant was recruited and trained for the study. The next stage was the real contact session where the concepts of drug abuse, prevention methods, psycho-education, assertiveness etc, were taught to the respective groups after the grouping of the participants into two experimental groups and a control group. The researcher with the aid of the instruments conducted the pre-test and post-tests.

\section{Lesson Contacts:}

The experimental group 1 was subjected to Assertiveness Training (AT) while Group 2 was Psycho-education Training (PT) and each group sessions were divided into five over a period of five weeks where each lesson took 45 minutes.

Objectives of the Therapeutic Programmes: To enlighten and help prevent the participants from drug abuse.

Summary of Intervention Programmes:

Assertiveness Training (AT)

Week 1: Introduction, Objectives and pre-testing

Week 2: Learning the Meaning and Concepts of Assertiveness

Week 3: Setting Goals for Assertive Behaviour and Assertive Rights

Week 4: How to be Assertive

Week 5: Evaluations and Post-testing

\section{Psycho-education Training:}

Week 1: Introduction, Objectives and Orientation of group members

Week 2: Substance Abuse and Mental Health Issues

Week 3: Signs and Symptoms of Drug Abuse

Week 4: Self-help for substance abuse

Week 5: Evaluations and post-testing

\section{Control}

Week 1: Introduction and administration of pre-tests

Week 2: Personal hygiene principles

Week 3: HIV/AIDS sensitization

Week 4: Career Guide 
Week 5: Administration of post-tests.

Data Analysis

Quantitative data were subjected to analysis of covariance to determine significant main effects of the treatment packages on drug abuse.

\section{RESULTS}

The effect of preventive measures (treatment) and sex on post-test scores of drug abuse was examined using ANCOVA with pre-test scores of drug abuse used as a covariate. The independent variables accounted for $73 \%\left(\mathrm{R}^{2}=\right.$ 0.73 ) of variance on post-test scores of drug abuse.

Table 2: Analysis of Covariance (ANCOVA) result

\begin{tabular}{|c|c|c|c|c|c|}
\hline Source of Variation & SS & DF & MS & $\mathbf{F}$ & P-Value \\
\hline Preventive measure & 7121.25 & 2 & 3560.63 & 6.88 & $0.003 *$ \\
\hline Sex & 165.75 & 1 & 165.75 & 0.32 & 0.575 \\
\hline Preventive Sex & 847.63 & 2 & 423.81 & 0.82 & 0.450 \\
\hline
\end{tabular}

$\mathrm{R}^{2}=0.73$, Adj. $\mathrm{R}^{2}=0.67,{ }^{*}=\mathrm{P}<0.05, \mathrm{SS}:$ sum of squares, DF: degree of freedom, MS: mean squares

There was a statistically significant main effect of preventive measures (treatment) on the post-test of drug abuse $\left(\mathrm{F}_{(2)}=6.88 ; \mathrm{P}<0.05\right)$. This implies that there was the main effect of treatment on prevention of drug abuse (Table 2). Therefore, the hypothesis which stated that there will be a significant main effect of treatment in the prevention of drug abuse is hereby confirmed.

Secondly, the result also shows that there was no statistically significant main effect of sex on the prevention of drug abuse $\left(\mathrm{F}_{(1)}=0.32 ; \mathrm{P}>0.05\right)$. The implication is that sex does not have an effect on the prevention of drug abuse (Table 2). Thus, the hypothesis which stated that there will be a significant main effect of sex on prevention of drug abuse is hereby rejected.

Lastly, the result also shows the interaction effect of treatment and sex on the prevention of drug abuse. There was no statistical significant interaction effect $(\mathrm{F}(2)=0.82 ; \mathrm{P}>0.05)$. This implies that treatment and sex do not have any interaction effect as regards the prevention of drug abuse (Table 2). Hence, the hypothesis which stated that there will be a significant interaction effect of treatment and sex on prevention is not confirmed.

\section{DISCUSSION}

The findings of the first hypothesis which states that there will be the significant main effect of treatment in the prevention of drug abuse among participants reveal that assertiveness and psychoeducation had a significant influence of drug abuse as prevention strategies adopted by secondary schools. This finding is consistent with that of Wesley \& Mattaini, (2008) that assertiveness training programmes are designed to improve an individual's assertive beliefs and behaviours, which can help the individual change how they view themselves and establish selfconfidence. This further corroborates Corey (2009) report that an assertiveness training programme is a systemic approach used to enhance more assertive self-expression, based on a balance between achieving one's own goals and respecting the needs of others. The intervention approach developed by Pentz (1983) is therefore based on the assumption that the initiation of substance use can be deterred by increasing social competence and self-efficacy. 
Social competence is essentially conceptualized as assertiveness (i.e., the ability to disagree, to refuse, to make requests, and to initiate conversations).

Tondo (2012) in a study on covert sensitization training and group therapy intervention showed that covert sensitization training and group therapy intervention was found to be effective in fostering tobacco smoking cessation among commercial motorcyclist in Ibadan. This finding is also consistent with that of Colom and Lam, (2005) on anxiety; Mackinnon, Griffiths and Christensen, (2008) that psycho-education is a cost-effective interventional approach that emphasizes teaching stress-coping strategies such as goal setting, skills teaching, satisfactory goal achievement, assertiveness and communication skills. These help to mitigate the development of depression. According to Colom and Lam (2005), psychoeducation focuses on the early identification of prodromal signs and possible predisposing and precipitating causes of these mental disorders. It also encourages individuals to explore their health beliefs and illness awareness and enables them to understand the complex relationships between symptoms, personality, interpersonal factors and environment. It further revealed the differential values of the pre and post-treatment outcome and equally showed the effectiveness of the treatment packages over the control (i.e. non-treatment group).

The findings of the second hypothesis which states that there will be the significant main effect of sex on prevention of drug abuse among participants, reveals that there was no statistically significant main effect of sex on prevention of drug abuse $\left(\mathrm{F}_{(1)}=0.32 ; \mathrm{P}>0.05\right)$. This implies that sex does not have an effect on the prevention of drug abuse. Thus the hypothesis which stated that there will be a significant main effect of sex on prevention of drug abuse is hereby rejected. Contrary to this finding, Brady and Randall (1999) reported that gender differences and similarities have significant treatment implications thus one can be tempted to conclude that sex has a significant effect on drug abuse prevention. Furthermore, (CSAP) Center for Substance Abuse Prevention (2001a) suggests the importance of better understanding and response to the special needs of girls and boys. Girls do appear to experience more internal manifestations of risk than boys, particularly in the mid-teen years thus suggests that more behavioural life skills orientations may be more effective in meeting the needs of girls at risk. Boys do appear to be more influenced by external factors in the social environment of their communities, and interactive programming as defined in this study appears an appropriate emphasis for boys. More investigation is important here.

The findings of the second hypothesis which states that there will be significant interaction effect of treatment and sex on prevention of drug abuse among the participants reveal that there was no statistically significant interaction effect $(\mathrm{F}(2)=0.82 ; \mathrm{P}>0.05)$. This also implies that treatment and sex do not have any interaction as regards prevention of drug abuse. Hence the hypothesis which stated that there will be a significant interaction effect of treatment and sex on prevention is not confirmed. This is contrary to reports by Botvin et al. (1990) that taking a prevention model for a specific population and making it culturally sensitive will increase its effectiveness to further improve existing prevention approaches by tailoring them to a particular population or sex.

\section{Conclusions}

i. Assertiveness has a significant effect as a measure of preventing drug abuse among secondary school students.

ii. Psycho-education has a significant effect as a measure of preventing drug abuse among secondary school students.

iii. Sex has no significant effect in preventing drug abuse among secondary school students.

iv. There is no significant interaction effect of treatment and sex in the prevention of drug abuse among secondary school students.

\section{Recommendations}

i. High premium should be placed on developing and mainstreaming prevention programs on drug abuse into the school curriculum in secondary schools for students to become more assertive and acquire more knowledge on drugs and its effects on mental health.

ii. More research is required in the area of sex as it influences the effectiveness of the treatment package to better understand and respond to the special needs of girls and boys. 


\section{References}

[1]. Botvin, G., J., Baker E., Filazzola A. D. \& Botvin, E. M. (1990). A cognitive-behavioral approach to substance abuse prevention: one-year follow-up. Addictive Behaviors, 15(0), 47-63.

[2]. Brady, K., T. \& Randall, C., L. (1999). Gender differences in substance use disorders. Psychiatr. Clin. North Am. 1999; 22:241-252.

[3]. Centre for Substance Abuse Prevention (2001a). Closing the gap between research and practice: Lessons of the first three years of CSAP's national CAPT system: 1997-2000. Rockville, MD: Author.

[4]. Colom, F., \& Lam, D. (2005). Psychoeducation: Improving outcomes in bipolar disorder. European Psychiatry, 20, 359-364.

[5]. Corey, G. (2009). Theory and practice of counseling and psychotherapy. 8th Edition. Belmont, CA; Australia: Brooks/Cole Cengage Learning, c2009.

[6]. David, W.S., Lorraine, M. \& Sacha, R. (2008). School-Based Drug Prevention Programs: A Review of What Works. Vol: 41(2):259-286.

[7]. Dixon, L. (1999). Dual diagnosis of substance abuse in schizophrenia: prevalence and impact on outcomes. Schizophr. Res. 35, S93-S100.

[8]. Gottfredson D., C. \& Wilson D., B. (2003). Characteristics of effective school-based substance abuse prevention. Prevention Science, 4(1), 27-38.

[9]. Iruloh, B. N. \& Amadi, G. N. (2008). Psychological Perspective of Drug Abuse, Prevention and Treatment. University of Port Harcourt Press, Port Harcourt, Nigeria.

[10].Jahromi, L. Mokri, A. \& Ekhtyari, H. (2009). Cardiovascular complications of opioid abuse. J Addict. 2009; 7:6978.

[11].Lam, D. H., Hayward, P., Watkins, E. R., Wright, K., \& Sham, P. (2005). Relapse prevention in patients with bipolar disorder: cognitive therapy outcome after 2 years. Am. J. Psychiatry. 162(2):324-9.DOI: 10.1176/appi.ajp.162.2.324

[12].Mackinnon, A., Griffiths, K. M. \& Christensen, H. (2008). Comparative randomised trial of online cognitivebehavioural therapy. British Journal of Psychiatry Jan 2008, 192 (2) 130-134;

[13]. Naderi S., H, Bynazadeh M, Safatian S. \& Peyvandi, A., A. (2009). Tehran: Center of Combing Substance Abuse; 2009. Comprehensive package of treatment of addiction; pp. 24-58.

[14].Pentz, M., A. (1983). Prevention of adolescent substance abuse through social skills. In: Glynn, T.J.; Leukefeld, C.G.; and Ludford, J.P., eds. Preventing Adolescent Drug Abuse: Intervention.

[15].Skinner, H., A. (1982). The Drug Abuse Screening Test. Addict Behav. Vol. 7(4):363-71.

[16].Tondo, M., J. \& Asuzu, C., C. (2012). Effects of Covert Sensitization and Group Therapy Intervention in Fostering Tobacco Smoking Cessation among Nigerian Commercial Motorcyclists in Ibadan. (In Press).

[17].Wesley, J. M. \& Mattaini, M. A (2008). Assertiveness Skills Education. http://www.peacepower.info/modules/RespectAssert.pdf Retrieved on 21/02/2010. 